\title{
VENTURA RODRÍGUEZ
}

\section{VENTURA RODRÍGUEZ}

Carlos Díaz Gómez: Universidad de Alcalá de Henares. Madrid (España) carlos_diazgomez@yahoo.com

\section{CURRÍCULUM VITAE}

Doctor en Filosofía por la Universidad Complutense de Madrid (España) con Premio Extraordinario, Licenciado en Derecho por la Universidad Complutense de Madrid (España) con Premio Extraordinario, Licenciado en Altos Estudios Constitucionales con Premio Extraordinario y Profesor de la Universidad Complutense de Madrid (España). Autor de numerosos libros y artículos en revistas especializadas y universitarias.

\section{RESUMEN}

Sobre el arquitecto español Ventura Rodríguez

\section{PALABRAS CLAVE}

Ventura Rodríguez - Enciclopedia Británica

\section{ABSTRACT}

About the Spanish architect Ventura Rodriguez 


\section{KEY WORDS}

Ventura Rodríguez - British Encyclopedia

TEXTO:

De los dos Rodríguez que figuran en la decimoquinta edición de la Enciclopedia Británica (1989), ninguno corresponde al arquitecto español Ventura Rodríguez, quien ahora sin duda estará muy orgulloso con su boca de metro nueva tan cerca del Palacio de Liria, en Madrid. Tampoco encontrará a Jorge Juan, ni a Isaac Peral (el auténtico inventor del submarino), porque no iban ahora los ingleses a decirle al mundo que fue un español, y no ellos ni los alemanes, ni los rusos con todo su potencial técnico y científico, quien un día concibió una idea magistral que volvió a cambiar la faz del mar y de la tierra. Tampoco encontrará al doctor Marañón, ni a tantos otros hombres y mujeres insignes. 


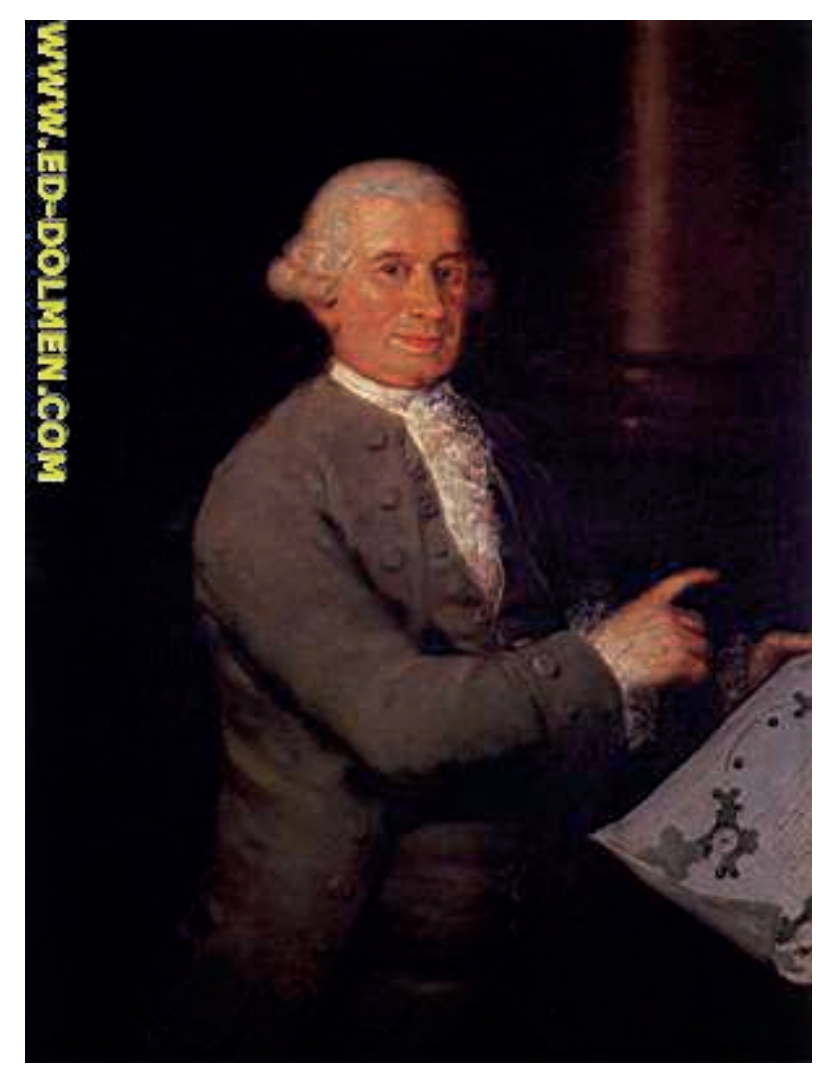

Retrato de Ventura Rodríguez por Goya

Conservado en el Museo Nacional de Estocolmo

Sí hay, sin embargo, un espléndido artículo sobre Inigo Jones, el arquitecto que alzó Banqueting House, en Londres. Cuando lo leí pensé que quizá Inigo era en realidad una derivación de Íñigo, un español que, sin saber gran cosa de su pasado, embarcó un día en San Sebastián, y arribó en Southampton para dejar en la gran ciudad una muestra de buen hacer.

Me pregunto si Covarrubias estará en el tomo 3.

Cisneros figura -hasta ahí podíamos llegar- junto a Jiménez de Quesada, quien, según la EB, se movía por interés material y no por magnanimidad. El artículo termina asegurando que Quesada murió de lepra, y que un libro que escribió en su retiro se perdió. Quizá alguien le prendió fuego. 